\title{
PRESENTACIÓN \\ PROCESOS POLÍTICOS EN CENTROAMÉRICA
}

\author{
Carlos Barrachina Lisón \\ Rubén Torres Martínez
}

Desde los años noventa la región centroamericana está experimentando un esfuerzo complejo de tránsito hacia un sistema que pretende llegar a ser democrático. Con la excepción de Costa Rica, en el que la democracia tiene una tradición mucho más arraigada, Guatemala, El Salvador, Nicaragua y Honduras, tras los conflictos bélicos de la década de los ochenta y principios de los noventa del siglo xx, están tratando en condiciones muy adversas lograr establecer un modelo de convivencia lo más democrático posible.

Las tensiones políticas tradicionales, las grandes desigualdades, la consolidación del crimen organizado y la violencia, ya sea ésta política o criminal, condicionan el desarrollo de estas sociedades, en las que si bien se concurre a procesos electorales de forma periódica, no han dejado de presentar irregularidades, sorpresas desagradables, e incluso, como en el caso de Honduras en el año 2009, la presencia de nueva cuenta de los militares como actores políticos determinantes.

En este número de la revista Península, en el que se conmemora el décimo aniversario de la misma, se presentan trabajos elaborados por académicos "jóvenes" de diferentes países centroamericanos. Ilka Treviño profesora de la Universidad de Costa Rica, analiza las elecciones que tuvieron lugar en febrero del 2014 en este país. Eduardo Fernández Luiña con un equipo de la Universidad Francisco Marroquín de Guatemala, hace un análisis sobre alguna de las características de la carrera profesional de los diputados guatemaltecos en las últimas siete legislaturas, señalando los problemas de la falta de continuidad de los mismos para la consolidación del proceso democrático. Elvira Cuadra, Directora Ejecutiva del Instituto de Estudios Estratégicos y Políticas Públicas de Nicaragua desarrolla un análisis histórico, desde la época de Somoza hasta la fecha de la evolución de las élites políticas nicaragüenses, explicando las raíces sobre las que se asienta la actual dinámica política de Nicaragua. Carlos Barrachina, profesor de la Universidad de Quintana Roo, en México presenta un artículo que combina diferentes variables del sistema político hondureño, centrando sus esfuerzos de análisis entre los años 2006 y 2014 . Presenta una explicación de la crisis política que alcanzó su apogeo 
en el año 2009, y que sin embargo no ha desaparecido todavía, complicándose si cabe con el aumento de la violencia homicida y con la cada vez más consolidada presencia del crimen organizado sobre el territorio hondureńo. Para cerrar esta primera parte del presente volumen Carlos Luis Sánchez y Sánchez nos propone un artículo en torno a la identificación partidista como un indicador de reciprocidad democrática, se trata del caso del Partido de la Revolución Democrática (PRD) en la ciudad de México durante su gestión 2000-2006. El autor, apegándose a datos empíricos, muestra la lógica de desempeño y reciprocidad por la vía de la política social, que el gobierno de Andrés Manuel López Obrador operó durante su sexenio. Esos artículos se complementan en este número monográfico con sendos artículos que resaltan la realidad cultural en Centroamérica centrándose en la producción poética, y con reseñas que analizan textos sobre la región.

Dos textos de corte literario se añaden al presente volumen, ambos sobre Guatemala, escritos por colegas centro americanistas especialistas en el país chapín y realizados desde el otro lado del atlántico. Vanessa Perdu de la Universidad de Aix-Marsella nos presenta cómo el cuento guatemalteco logra reflejar y reproducir realidades y experiencias sobre el exilio guatemalteco contemporáneo. Tres autores analizados a la sombra de lo que pareciese un "país perdido" tanto en términos materiales como simbólicos. Aunado a esto la visión de los autores que combinan y entremezclan fuentes y acontecimientos verídicos con situaciones imaginarias o "sońadas". La autora logra mostrar la poderosa relación existente entre literatura y política, entre ficción y realidad en la Guatemala que va desde la segunda mitad del siglo xx hasta nuestros días. Por su parte Dante Barrientos-Tecún se lanza sobre el estudio de dos autoras guatemaltecas poco conocidas: Ana María Rodas y Rossana Estrada Búcaro. De distintas generaciones literarias y con distintas tradiciones de escritura, ambas abordan la construcción de la individualidad femenina sin forzosamente acudir de manera exclusiva al discurso de género. El autor basándose en dos poemarios, avanza sobre cómo los regímenes autoritarios moldean estructuras sociales, usos, costumbres, valores que condicionan el desarrollo de las prácticas literarias.

Tres reseńas sobre textos que tienen que ver con el área geográfica centroamericana cierran este volumen de aniversario.

En los momentos en los que se escribe esta presentación se habla con esperanza de la "primavera guatemalteca", por la movilización popular que ha logrado que el Presidente Otto Pérez Molina haya tenido que renunciar al cargo y se haya presentado a la justicia para rendir cuentas por severas acusaciones de corrupción. La comunidad internacional ha celebrado esta movilización popular que ha derrocado a un ex militar representante electo de un partido de "derechas". Sin embargo y a pesar de la oportunidad que ofrecían las elecciones del 6 de septiembre del 2015 para que el pueblo seleccionara nuevas opciones, los tres candidatos que obtuvieron los primeros lugares en las elecciones representan la "vieja" política guatemalteca y no se salen de la hoja de ruta que las elites de este 
país han marcado a lo largo de los ańos, por lo que no se esperan grandes cambios que respondan a la inquietud popular.

La renuncia al cargo del general Otto Pérez Molina en 2015, al que el Congreso le retira la inmunidad para ser sometido a juicio, y el golpe de estado en contra de Manuel Zelaya Rosales en Honduras en 2009 tienen algunos puntos en común en su origen: los dos presidentes perdieron la confianza del Congreso y fueron reclamados por la justicia de sus países. También tienen aspectos que los diferencian. Mientras que los sectores sociales que apoyaban a Molina lo abandonaron frente a las acusaciones y lo llevaron a su renuncia; en el caso de Zelaya los sectores populares que lo respaldaban, con el apoyo de la izquierda bolivariana latinoamericana no lo abandonaron. Ello llevó, como se analiza con detalle en el artículo que se presenta en este número, a que los militares actuarán protagonizando un golpe de estado al extraer al Presidente del país, en lugar de presentarlo ante las autoridades judiciales como les había sido ordenado.

La dinámica política hondureña, como la guatemalteca ha asimilado la tensión y el descontento popular, cambiando, pero sin cambiar. Las elites tradicionales se siguen manteniendo en el poder y manejan la política nacional a su antojo.

En ambos países, pero también en el resto de Centroamérica, la importancia del narcotráfico y del crimen organizado sobre las circunstancias es muy importante, creciente y difícil de medir. Es por ello que esfuerzos como el de este número monográfico deben de ser frecuentes. Es necesario que en México conozcamos y analicemos lo mejor posible las inercias y tensiones que condicionan la política de Centroamérica, una región con la que compartimos no sólo fronteras, sino flujos migratorios, problemas derivados de la inseguridad y realidades económicas similares e interconectadas.

Esperamos que este número llene las expectativas de los lectores, y que los diferentes aspectos que se analizan permitan ofrecer motivos de reflexión y análisis sobre la difícil dinámica de profundización de la democracia en México y la región de Centro América. 
